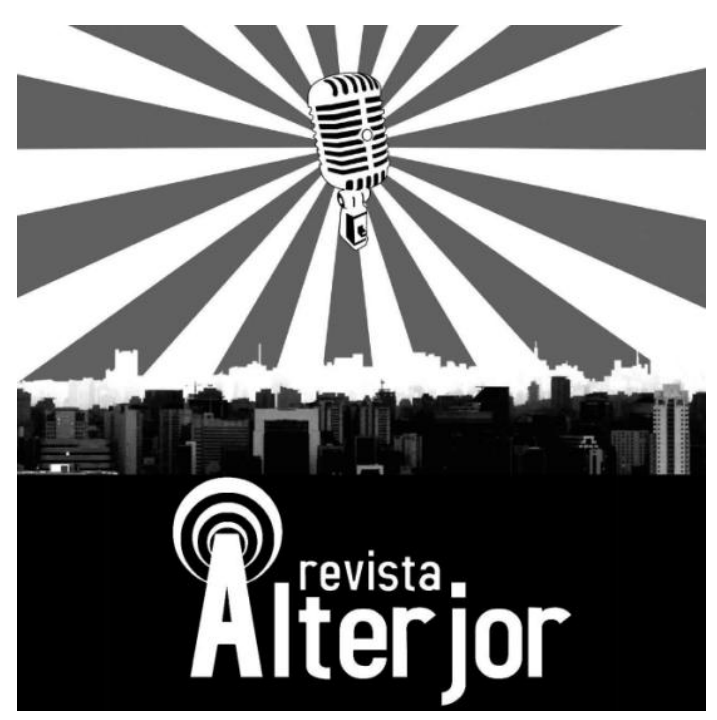

\title{
O QUE PODEMOS APRENDER COM O PENSAMENTO MÍTICO PRESENTE NAS OBRAS CLÁSSICAS?
}

\author{
André Luiz Pullig Viana ${ }^{1}$
}

RESUMO: As obras clássicas oferecem farto material que nos ajuda a entender o pensamento mítico e sua influência até os nossos dias. Diametralmente à razão, esse pensamento oferece ao homem a confiança de que suas ações podem ser preponderantes às respostas do mundo natural, além de fixar modelos para todas as funções e atividades humanas. O mito, portanto, é uma atribuição de sentido ao mundo, apoiado no efeito psicológico e na imaginação humana, capaz de infligir ao homem acomodação em seu habitat, enquanto parte de um grupo social. Por meio da existência dos outros ele se afirma e essa afirmação se dá não somente por meio da sua razão, também, por meio das suas crenças. Este trabalho pretende, dessa forma, apresentar o que podemos aprender com pensamento mítico presente nas obras clássicas.

PALAVRAS-CHAVE: Clássico. Mito. Pensamento.

ABSTRACT: The classical works offer abundant material that helps us to understand mythical thinking and its influence to this day. Diametrically to reason, this thought offers man the confidence that his actions can be preponderant to the responses of the natural world, in addition to setting models for all human functions and activities. The myth, therefore, is an attribution of meaning to the world, supported by the psychological effect and human imagination, capable of inflict accommodation on man in his habitat, as part of a social group. Through the existence of others he asserts himself and this affirmation is not only through his reason, also through his beliefs. This work intends, in this way, to present what we can learn from mythical thinking present in classical works.

KEYWORDS: Classic. Myth. Thought.

\footnotetext{
${ }^{1}$ Filósofo, Teólogo e Psicanalista; Pós-graduado em Língua Portuguesa, Psicopedagogia e Psicanálise Clínica. Presidente da Academia de Letras do Brasil (ALB/DF). Autor dos livros: Poetizar; Cancioneiro; Fazer Literário: desafios e realizações; Tua Voz; Sonhos para liberdade; e Manuel, minha Bandeira é a prosa. E-mail: andrepullig@yahoo.com.br. Lattes: <http://lattes.cnpq.br/8755108996726962>
}

\section{Revista ALTERJOR}

Grupo de Estudos Alterjor: Jornalismo Popular e Alternativo (ECA-USP)

Ano 10 Volume Ol Edição 23 Janeiro-Julho de 2021

Avenida Professor Lúcio Martins Rodrig̉ues, 443, Cidade Universitária, São Paulo, CEP: 05508-020 


\section{INTRODUÇÃO}

Ítalo Calvino escreveu um capítulo muito interessante em seu livro Por que ler os clássicos. Nesse capítulo de título homônimo ao livro, ele afirma que "Os clássicos são aqueles livros dos quais, em geral, se ouve dizer: 'estou relendo...' e nunca 'Estou lendo'”. Eis aí o primeiro desafio de ser perscrutar os textos clássicos: são livros que não têm sua leitura esgotada com facilidade. Ele também diz: "Dizem-se clássicos aqueles livros que constituem uma riqueza para quem os tenha lido e amado; mas constituem uma riqueza não menor para quem se reserva a sorte de lê-los pela primeira vez nas melhores condições para apreciá-los". Por isso os clássicos são relidos e revisitados de tempos em tempos, pois na juventude, muitos de nós, não temos todas as condições de ânimo e capacidade para apreendermos os valiosos conhecimentos que eles nos trazem. Calvino continua dizendo que:

\footnotetext{
"Os clássicos são livros que exercem uma influência particular quando se impõem como inesquecíveis e também quando se ocultam nas dobras da memória, mimetizando-se como inconsciente coletivo ou individual", pois "Um clássico é um livro que nunca terminou de dizer aquilo que tinha para dizer". (CALVINO, 1993)
}

Diz mais: "Os clássicos são aqueles livros que chegam até nós trazendo consigo as marcas das leituras que precederam a nossa e atrás de si os traços que deixaram na cultura ou nas culturas que atravessaram”. Daí nos perguntarmos, por exemplo, se os significados das aventuras dos heróis homéricos são, apenas, produtos da nossa realidade interpretativa. $\mathrm{O}$ autor dessas citações áureas recomendará beber sempre na fonte genuína dos textos clássicos e referir-se-á ao verbete "clássico" constante na Enciclopédia Einaudi de Franco Fortini como sendo um efeito de ressonância que vale tanto para uma obra antiga quanto para uma moderna, mas já com um lugar próprio numa continuidade cultural.

Neste artigo, visitaremos com a economia que o trabalho requer alguns clássicos da antiguidade: Homero, Platão e Virgílio. Faremos um complemento com um autor do século XIX: Antonin-Gilbert Sertillanges. Veremos como é possível dialogarmos com esses autores, nos dias atuais, e o que podemos aprender com eles. 


\section{DESENVOL VIMENTO}

Ao lermos Homero, inferimos que a vida será sempre uma eterna epopeia. Não nos faltarão heróis, vilões, amor, ódio, vingança, justiça, trapaça, coragem. O que importa é o que fazer com esses elementos quando for preciso vestirmo-nos com suas respectivas máscaras.

Esse autor clássico nos propõe um dos grandes dilemas da vida: ou morremos velhos e ignóbeis, sem nada deixarmos para a posteridade ou novos e heroicos, perpetuando nosso legado. Essa metáfora diz mais respeito ao modo como vivemos do que como nascemos ou morremos. As grandes questões são: o que deixaremos de bom para a posteridade? Estamos transformando, significativamente, o mundo a nossa volta? Somos protagonistas da nossa história ou meros expectadores?

Aquiles dirá muito sobre as nossas escolhas. A argúcia do Ulisses também nos mostra que mesmo que tudo pareça contrário sempre haverá uma saída. Basta-nos uma resolução estoica e as peças do xadrez da vida humana começam a se mover no tabuleiro da nossa existência. A roda gigante não para. Isso nos faz indagar: quantos futuros podemos construir? Esta capacidade futurista diz respeito a todos nós.

Carpeaux, dizia que o termo futurista servia para demostrar a diferença qualitativa entre nós e os homens do passado, entre as nossas expressões e as dele, ao mesmo tempo em que negava continuações do passado, ou seja, a própria continuidade da história. Daí chegarmos à igualdade dos homens em todos os tempos. $\mathrm{O}$ que vai nos diferenciar é a nossa capacidade de construir e transformar, de maneira positiva, a sociedade em que vivemos.

A Ilíada é o retrato de nossas próprias lutas pessoais: a ira de Aquiles, a prudência de Ulisses, a sabedoria de Nestor, a fraqueza de Páris, a coragem de Heitor. Seus deuses, ideais humanos, desmascaram a própria natureza humana e nos mostra que podemos superá-la, caso queiramos.

Zeus não precisaria temer à grandeza dos filhos. Qual pai não deseja o melhor à sua prole? Isso talvez tivesse evitado a guerra troiana. Além do mais, o que tinha Páris com a contenda entre as deusas Hera, Atena e Afrodite? Se não tivesse sido escolhido para resolver a contenda entre elas, talvez não conseguisse o poder de seduzir Helena. 
Como ficam as nossas escolhas, se somos meros joguetes nas mãos dos poderosos, sejam eles deuses, reis, legisladores? O que restará de realmente nosso se o que somos é o resultado da soma de experiências outras?

Fato é que sempre existirá uma Helena, um Aquiles, um Menelau, um Agamenon, um Heitor, um Páris, um Ulisses. Sempre haverá alguém com a necessidade imperiosa de possuir o que é mais belo e agradável, mesmo que pertença a outro. Sempre haverá a irá, os estratagemas, a tirania e a justiça. A tirania que já foi, inclusive, utilizada pela própria Grécia, em detrimento da democracia e, ainda hoje, há homens que a veem como um instrumento de poder.

Os clássicos, por sua característica atemporal, podem sempre nos ensinar lições importantes para a vida cotidiana. Platão afirmou que a tirania era a marca da ilegalidade. Por meio dela seu próprio mestre, Sócrates, fora morto.

Rousseau dirá que a democracia, olha aí nossa Helena vestida em outra roupagem, degenera-se em oclocracia, governo da pleble; a aristocracia em oligarquia, governo de pequenos grupos; a realeza em tirania, pois um tirano é um indivíduo que se arroga a autoridade real sem ter direito a ela. Montesquieu dirá que existem duas formas de tirania: uma real, promovida por governos, e outra de opinião, quando a política fere o modo de pensar de uma nação.

Etiene de La Boétie afirmará que as pessoas submetem-se à tirania porque ela reside nelas próprias, em seus espíritos de servidão voluntária. De outra forma, o nosso dever de agir deve ser exemplo para todos. Precisamos defender o direito a uma liberdade de consciência plena, pois para evoluirmos do estado de natureza ao estado civil é preciso crescimento ético e moral.

Sócrates afirmava que o saber era a força que conduzia o homem à ação. Assim sendo, o homem virtuoso portaria em si todas as formas de virtude, uma vez que o conhecimento de uma virtude serviria de fundamento para as demais. Isso é necessário para que entendamos o que seja virtude. Não a virtude como um dom divino, mas a virtude como saber, de forma que a percepção do bem e do mal possa se construir, em nosso espírito.

O fato é que nem as ciências religiosas nem a lírica pedagógica conseguiram, ainda, elevar o pensamento humano ao plano necessário. Talvez, por isso, Dante tenha lançado a muitos em seu famoso inferno. 


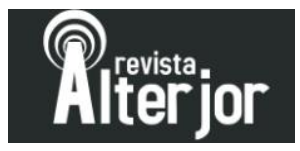

Copérnico mostrou que a Terra não era o centro do universo, assim como o homem também não. Darwin pretendeu quebrar a prepotência humana ao ligar sua espécie ao restante dos animais. Freud mostrou que o EGO não só não é dono do mundo nem da espécie, como também não é senhor de si próprio. Para aonde iria o homem após essas revelações, diante do caos?

Precisamos aprender a pensar e a refletir, rigorosamente, sobre nossa existência. Morin (2007) dirá que "A cultura humanista é uma cultura geral que, por meio da filosofia, do ensaio e da literatura coloca problemas humanos fundamentais e incita à reflexão".

Para tanto, podemos nos valer das obras clássicas e da própria Filosofia. O termo filósofo foi atribuído a Pitágoras, por Leonte, rei dos Ilíacos quando afirmou ser, o dono do teorema "quadrado da hipotenusa é igual à soma do quadrado dos catetos", sábio, ao que recebeu como resposta ser, aquele, apenas amante da sabedoria.

Aristóteles dirá que a Filosofia é o saber que se busca. Kant dirá que a Filosofia buscará responder a três perguntas: o que posso conhecer? O que devo fazer? O que me cabe esperar? Resumidamente, o que é o homem? Daí decorrem as seguintes questões que se encontram latentes nas mentes dos homens: quem sou? De onde venho? Para onde vou?

Podemos tentar responder a essas questões, recorrendo aos textos sagrados, à Gnosiologia, à Lógica, à Epistemologia, à Cosmologia, à Ontologia ou até mesmo à Metafísica.

Vita dirá que o homem é um ser constitutivamente crítico, pois vive pessoal ou historicamente num estado último de insegurança, ou seja, o homem será sempre um problema para si próprio. Daí a Filosofia grega ter surgido de uma crise espiritual, da necessidade de distinção entre a Filosofia e a religião. Por isso, os primeiros filósofos acreditarem que os princípios que constituíam o mundo físico eram os mesmos que constituíam os homens.

O pensador exercerá sua função dentro de uma época e sob circunstâncias muito particulares. Rousseau, por exemplo, afirmará que a natureza é boa e a civilização má, que pela natureza todos os homens são iguais e tornam-se desiguais graças às instituições criadas pelas classes. Nietzsche afirmará que a natureza está além do bem e do mal e que, pela natureza, todos os homens são desiguais.

Revista ALTERJOR

Grupo de Estudos Alterjor:Jornalismo Popular e Alternativo (ECA-USP)

Ano 10 Volume Ol Edição 23 Janeiro-Junho de 2021

Avenida Professor Lúcio Martins Rodrig̉ues, 443, Cidade Universitária, São Paulo, CEP: 05508-020 


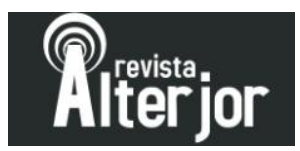

O filósofo Platão foi o primeiro a reconhecer a diferença entre uma realidade imanente e uma transcendente em sua Filosofia. Ele estabeleceu a distinção entre duas realidades: uma realidade material e sensível e outra realidade imaterial e suprassensível.

A alegoria da caverna, de Platão, nos servirá como exemplo de conhecimento transcendente. Ela retrata a condição de pessoas presas pelos pescoços, de forma a só olharem para frente. Atrás delas, um muro e uma fogueira. Algumas pessoas transitam entre o muro e a fogueira, carregando objetos cujas sombras são projetadas na parede ao fundo da caverna e à frente delas. Dessa forma, inexiste a possibilidade de se desenvolverem a consciência plena porque as formas comparativas são escassas. As sombras são projetadas pelos amos da caverna. Esses, não querem libertar a ninguém da ignorância. Divertem-se com a condição dos agrilhoados. Agora imaginem que, por um impulso intuitivo, alguém consiga libertar-se à contemplação de coisas além do que imaginava e resolva sair da caverna, mesmo contra a opinião dos demais.

Abramos um parêntese quanto ao que diz Antonin-Gilbert Sertillanges sobre o labor da aprendizagem. Sertillanges, filósofo e teólogo francês, discorreu em seu livro A vida intelectual que o intelectual é um consagrado, ou seja, separado, pois o exercício da erudição requer muita reflexão sobre os mais variados e importantes temas, sejam de caráter histórico, científico ou puramente filosófico. No aspecto da organização da vida, ele recomenda a simplificação, a cooperação com os iguais e a manutenção somente das relações necessárias, pois não devemos sacrificar nossas preciosas horas com assuntos inferiores. Sertillanges afirma: "o silêncio é o conteúdo secreto das palavras importantes. O valor duma alma mede-se pela riqueza do que ela não diz". Afirmou ainda ser possível encontrar a verdade em toda a parte porque todas as coisas estão ligadas entre si. O segredo é ter a mente em constante expectativa.

Em um capítulo importante da sua obra diz sobre a ciência comparada: "precisais passar de um espírito a outro, a fim de corrigi-los um pelo outro; precisais variar as culturas para não cansar o solo". E nos aconselha: "o espírito do homem pode chegar ao infinito, só a preguiça põe limites à sua sabedoria e às suas invenções", pois "o homem forte ergue diante de si a escada de Jacó, para a subida e descida dos anjos que nos visitam".

O pensador, além de humildade, precisa ser paciente ao que nos oferece a natureza de espírito e da inspiração. Nisto consiste o trabalho profundo: em mergulharmos de tal modo na verdade, de maneira que só nos reste a verdade.

Revista ALTERJOR

Grupo de Estudos Alterjor:Jornalismo Popular e Alternativo (ECA-USP)

Ano 10 Volume Ol Edição 23 Janeiro-Junho de 2021

Avenida Professor Lúcio Martins Rodrig̉ues, 443, Cidade Universitária, São Paulo, CEP: 05508-020 


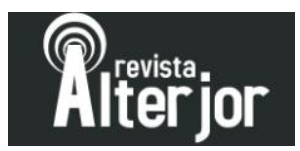

Em relação à preparação para o trabalho, o sábio reafirma o valor da leitura, por ser ela o meio universal para o aprendizado. Daí a importância do princípio da seleção, pois existem leituras para formação, informação, distração e edificação. E lembra: "quando se trata de formação, o que interessa não são os pensamentos, mas as verdades. Não são homens, mas as obras por eles realizadas e o que fica delas".

Quanto à organização da memória, Sertillanges nos orienta a arquivarmos na memória aquilo que possa nos ajudar em nossas ações:

"uma regra capital consiste em introduzir a memória na corrente da vida intelectual, em levá-la a tomar parte na vocação, de sorte que se especialize como o espírito, na mesma medida e com a mesma concentração que ele". (SERTILLANGES, 2015)

Segundo ele, existem quatro maneiras para se ordenar e reter os conhecimentos na memória: $1^{\circ}$ ) ordenar o que se quer reter; $2^{\circ}$ ) aplicar isso ao espírito; $3^{\circ}$ ) meditar nisso com frequência; e $4^{\circ}$ ) no ato da reminiscência, tomar pela extremidade a cadeia das dependências, que o resto seguir-se-lhe-á. Quando se tratar de um livro, não o feche sem que lhe seja possível resumi-lo e apreciá-lo.

Sobre o trabalho criador, observa que a arte de escrever exige longa aplicação que se converterá em hábito mental. "O segredo de escrever consiste em colocar-se ardentemente diante das coisas, até que elas vos falem e determinem os termos que as devem exprimir". Esse trabalho deve ser feito com constância, paciência e perseverança, porém o sábio autor adverte que o que mais importa na vida, não são os conhecimentos, é o caráter, e o caráter estaria ameaçado, se o homem se mantivesse debaixo do seu trabalho oprimido pelo rochedo de Sísifo.

Voltemos ao homem da caverna. Imagine que o indivíduo tenha se soltado e conseguido, com muita dificuldade, sair dela. A luz do sol o cega. Ele então procura ajustar sua visão, olhando para as águas. A primeira coisa que vê é a si próprio. Se quiseres conhecer os mistérios da vida e do universo, comeces olhando para dentro de si.

Somente depois que o homem já estiver acostumado a ver a luz do sol é que poderá conhecer, verdadeiramente, tudo a que se propõe. Pense que essa luz representa a ideia do bem que te levará a conhecer a verdade.

Revista ALTERJOR

Grupo de Estudos Alterjor:Jornalismo Popular e Alternativo (ECA-USP)

Ano 10 Volume Ol Edição 23 Janeiro-Junho de 2021

Avenida Professor Lúcio Martins Rodrig̉ues, 443, Cidade Universitária, São Paulo, CEP: 05508-020 
Imagine, agora, que esse homem queira retornar à caverna para alertar os demais que tudo que veem não passa de ilusão, um jogo de sombras. Ele terá de adaptar-se às sombras novamente, pois saíra de debaixo da luz do sol, símbolo do bem. Quantos acreditarão nele? Quantos quererão machucá-lo? Quantos discordarão dele? Imagine-o diante da escravidão inconsciente dos seus antigos companheiros, mas ele pensa que se somente um quiser ouvi-lo, apenas um, já terá valido a pena. Afinal, todos têm o direito de viver uma vida melhor, mais feliz e mais justa.

Analisemos, por exemplo, o uso de máscaras. É possível usá-las por diversos fatores e para diversos fins. Em Veneza, por exemplo, durante o primeiro milênio, elas eram usadas em uma festa parecida com o nosso carnaval. Essa festa era realizada antes da quaresma. Os gregos e romanos também usufruíram de festejos similares.

Em Veneza, existia uma classe de artesãos que eram responsáveis pela produção das máscaras que seriam usadas durante o carnaval: os "mascareri”. A festa representava um momento em que era possível transmutar a própria identidade e encarnar outros personagens, pelo fato de esconderem seus rostos.

A máscara masculina era, normalmente, triangular, com uma abertura por onde era possível comer, beber e falar. O modelo feminino era oval. (muito sugestivo). Na parte interna da máscara das mulheres, havia um botão o qual deveria ser preso com a boca, o que as impedia de comer, beber e falar.

Estamos falando da Veneza do primeiro milênio, porém parece a sociedade do século presente? A humanidade já vivenciou guerras, grandes, e diversas outras de menores proporções, embora não menos danosas; mas continua a celebrar sua eterna pré-quaresma. Os homens vivem um "carnaval" interminável. Insistem em manter suas diversas máscaras, deliberadamente, e o que é pior, muitas mulheres ainda não conseguiram, sequer, o poder de falar, pois as máscaras impostas a elas impedem-nas de exercerem esse direito. Enfim, a pandemia provocada pelo Covid-19 igualou a todos. Voltamos a usar máscaras.

Dessa vez, precisamos refletir além dos fatores sanitários.

"A pandemia legitimou um desenvolvimento de sofisticadas tecnologias de controle de vida e dos movimentos das pessoas, cuja eficiência foi comprovada em escala planetária. A implementação desses controles sociais tão estritos só foi possível porque houve medidas de exceção que legitimaram socialmente sua implantação e experimentação. A pandemia, 
independentemente de outras valorações, está sendo um grande laboratório de experimentação de técnicas biopolíticas de controle social, que em tempos de 'normalidade' não poderiam ser implantadas. Uma vez realizado o experimento laboratorial da eficácia do controle social das novas tecnologias, fica a suspeita fundada de que num futuro próximo só restará encontrar argumentos que legitimem aplicá-las como dispositivos normais da convivência cidadã para maior segurança de todos. A segurança foi o dispositivo que desde o século XVII serviu para legitimar a implantação de sucessivas tecnologias biopolíticas de controle social. Em nome da segurança a exceção se torna norma, e o excecional é vivido como nova normalidade.”. (RUIZ, 2020)

Esperamos ansiosos pelo momento em que todas as pessoas possam livrar-se, definitivamente, de todas as suas máscaras. Depois de tanto tempo usando-as, já estamos nos acostumando a não reconhecermo-nos como os seres únicos que somos.

De acordo com Aristóteles, para se alcançar a verdade científica seriam necessárias normas de pensamento que permitiriam demonstrações irrefutáveis. Por isso, o Órganon foi desenvolvido. A partir daí, as relações metafísicas matéria-forma, potência-ato passariam a comandar a visão aristotélica do homem. Dessa forma, o objeto da investigação ética seria o de desvendar a causa primeira da existência humana.

Entremos agora a analisar, brevemente, a obra Eneida, de Virgílio. Cabe aqui ressaltar que na idade clássica a poesia era considerada uma forma sagrada de expressão. Para se eternizar algo um dos caminhos era escrever sobre isso na forma de poemas, afinal o belo atrai a atenção e o gosto.

De acordo com Voltaire, a Eneida é uma das mais belas obras poéticas escritas em todos os tempos. Foi encomendada por Octávio Augusto que pretendia unir o espírito heroico troiano ao filosófico grego, a fim de dar ao povo uma identidade mítica. Dessa forma, a Eneida seria a história mítica de Roma desde Troia.

Essa história, segundo lembra alguns estudiosos do tema, tem sua verdade fundamentada no bem que pretendia produzir e não, necessariamente, nos fatos, pois poetas como Virgílio possuíam um conhecimento que o fazia crer que o espírito da Eneida representava o espírito de Roma.

A obra foi assim chamada por causa da narrativa em torno do herói troiano Eneias, sobrevivente da guerra de Troia e filho da deusa Vênus. Ela guarda, com as devidas proporções, estreita relação com a Ilíada e a Odisseia. Na primeira parte, inclusive, durante a 


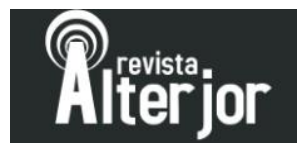

viagem de Eneias para Roma, ele passa pela ilha dos ciclopes, por Ítaca, começa uma construção em Creta, mas descobre que seu destino não era ali.

Vai aportar em Cartago e é recebido pela rainha Dido que acaba por apaixonar- se por ele que conta a ela como escapou, durante a queda de Troia, levando consigo seu filho e seu pai, ocasião em que perdera sua esposa Creusa.

Após um tempo em Cartago, Eneias recebe uma mensagem do deus Júpiter na qual deveria prosseguir sua viagem. Ele sai sem se despedir da rainha Dido que se suicida, por saudade e desgosto.

Anquises, pai de Eneias, morre quando passam pela Sicília e o herói troiano vai aportar na cidade de Cumas. Lá ele pede a uma sacerdotisa, uma Sibila, que o leve à presença do seu pai, no reino de Plutão, o hades grego. Anquises, então, mostra ao herói o futuro: a grande nação que Eneias haveria de construir.

Ao chegar à região do Lácio, o rei Latino lhe oferece, em aliança, a mão da filha, Lavínia, em casamento. Isso causou um grande problema, pois Turno, rei dos Rútulos, era o pretendente dela. Daí inicia-se uma guerra sem precedentes, de onde inferimos a semelhança desta empreitada com a própria guerra de Troia.

Eneias, então, busca aliança com Evandro, rei de Palenteia, a fim de se fortalecer em batalha. $\mathrm{O}$ estratagema dera certo. $\mathrm{O}$ livro narra ainda a preparação de um escudo para $\mathrm{o}$ guerreiro troiano pelo deus Vulcano e, após a morte de Palante, príncipe de Palenteia, Eneias se engaja definitivamente e com muita fúria na batalha. Tal episódio lembra a morte de Pátroclo, na Ilíada.

A guerra fica ainda mais sangrenta, de forma que Turno convida Eneias para um combate direto. $\mathrm{O}$ vencedor desposaria Lavínia.

Antes disso, porém, havia a necessidade de se derrotar Camila, do exército dos Volscos, uma guerreira praticamente invencível, contudo o exército de Eneias consegue derrotá-la e ele consegue também derrotar Turno e casar-se com Lavínia. Fundam uma cidade chamada Lavínia em homenagem à esposa e vivem nela até o fim dos seus dias.

Ascânio, filho de Eneias, mais tarde, sai da cidade natal e funda outra em Alba Longa. Dez gerações depois, Amúlio destrona seu irmão Nomitor e mata todos os seus sobrinhos para não reivindicarem o trono. Ele aprisiona Reia Sílvia, sua sobrinha, para que ela não gere filhos, 


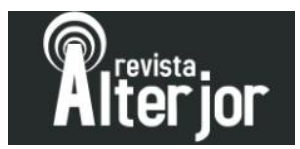

porém ela engravida de deus Marte e gera dois gêmeos: Rômulo e Remo. A partir daí todos já conhecem o restante da história dos gêmeos cuidados pela loba.

\section{CONCLUSÃO}

Retornemos aos significados das aventuras dos heróis homéricos. Eles estão implícitos no texto ou são produtos da nossa realidade interpretativa? Apliquemos isso aos demais heróis criados por outros escritores e ao homem da caverna, de Platão, que conseguiu libertar-se das sombras e, ao sair da caverna, contemplou a luz do sol e toda a verdade que ela o trouxe. Pensemos como a arte imita a vida. Daí poderemos tirar valiosas lições que nos levarão a entender o quanto os mitos e os símbolos têm a nos ensinar.

O nosso movimento Simbolista, por exemplo, movimento literário que começou no final do século XIX e antecedeu o Pré-Modernismo, nos diz muito sobre a nossa condição àquela época. O movimento ocorreu-nos quando o país estava passando por uma transição política da Monarquia para a República e o mundo prestes a desencadear uma Grande Guerra. Seu precursor, do Simbolismo, Charles Baudelaire, escritor de As flores do mal (1857), reafirmara a "decadência" dos valores positivistas e do cientificismo trazido pelo Naturalismo.

Aqui, o Movimento inicia-se com a publicação de Missal (1893) e de Broquéis (1893), de Cruz e Sousa e fica marcado por traços de espiritualidade, pessimismo, sinestesias, aliterações e excesso de metáforas. Quando entendemos a arte e as obras clássicas, em todos os períodos, fica-nos mais fácil entendermos a própria vida.

Os autores simbolistas buscavam a volta para um mundo interior, subjetivo. Podemos perceber esse fato ao analisarmos as poesias de Augusto dos Anjos, por exemplo.

O misticismo e a religiosidade predominante nas obras literárias dos Simbolistas requerem uma visão do sagrado e do espiritual, surgindo a apreciação pelo oculto, pelo mistério, o noturno, negando o materialismo da época.

O mito, entre os povos primitivos, era uma forma de situá-los no mundo. Sua verdade teórica não obedecia à lógica, nem à verdade empírica, nem à científica. Era verdade intuída. Arriscaríamos a dizer que não foi diferente com os nossos simbolistas, assim como não o é em nossos dias. Ele nasce do desejo de dominação do mundo, para afugentar o medo e 


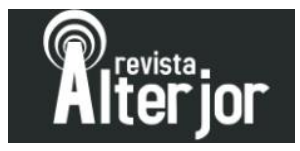

a insegurança. $\mathrm{O}$ homem, à mercê das forças naturais, que são assustadoras, passa a emprestarlhes qualidades emocionais.

O pensamento mítico está, então, muito ligado ao desejo que as coisas aconteçam de um determinado modo. Além de acomodar e tranquilizar o homem em face de um mundo assustador, dando-lhe a confiança de que, através de suas ações, o que acontece no mundo natural depende, em parte, dos atos humanos. O mito também fixa modelos exemplares de todas as funções e atividades humanas. É uma atribuição de sentido ao mundo, sobre a qual a afetividade e a imaginação exercem grande papel e cuja função principal não é explicar a realidade, mas acomodar o homem ao mundo, pois o sujeito só tem consciência, ele só se conhece enquanto parte do grupo e sua aceitação acontece não apenas por meio da razão, também por intermédio da fé e da crença.

Assim é criado o tabu, envolto em clima de temor e sobrenaturalidade, cuja desobediência é grave. Só os ritos de purificação, nos quais o pecado é transferido para outrem, podem restaurar o equilíbrio da comunidade e evitar que o castigo dos deuses recaia sobre todos.

O pensamento crítico e reflexivo e o desenvolvimento do pensamento científico ocuparam o lugar do conhecimento e renegaram o modo mítico de nos situarmos no mundo. Essa foi a posição defendida por Augusto Comte, fundador do positivismo. Assim, ao opor o poder da razão à visão ingênua oferecida pelo mito, o positivismo empobreceu a realidade humana, pois o homem não é só razão, mas também afetividade e emoção. Negar o mito é negar uma das formas fundamentais da existência humana, pois ele e a razão se complementam.

\section{REFERÊNCIAS BIBLIOGRÁFICAS}

ARISTÓTELES. Poética. Tradução Eudoro de Souza. 1. ed. São Paulo: Abril Cultural, 1973 (Coleção Os Pensadores).

ARISTÓTELES. Órganon: Categorias, Da Interpretação, Analíticos anteriores, Analíticos posteriores, Tópicos, Refutações sofísticas. Tradução, textos adicionais e notas de Edson Bini. Bauru: EDI-PRO, 2005.

AZEVEDO, Fernando. Formar leitores das teorias às práticas. Lisboa, Lidel, 2007.

BAUDELAIRE, Charles Pierre. As flores do mal. apresentação Marcelo Jacques tradução, introdução e notas Ivan Junqueira. Rio de Janeiro: Nova Fronteira, 2012. 


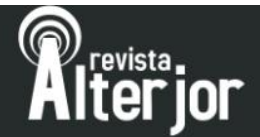

BOSI, Alfredo. História concisa da literatura brasileira. São Paulo, Cultrix, 2012.

CALVINO, Ítalo. Por que ler os clássicos. São Paulo: Companhia das Letras, 1993.

CAMUS, Albert. O Mito de Sísifo - Ensaio sobre o absurdo. Rio de Janeiro: Editora Record, 2008.

CARPEAUX, Otto Maria. História da literatura ocidental. 4 v. São Paulo: Leya Livros, 2011.

DE LA BOÉTIE, E. Discurso da servidão voluntária. São Paulo: Brasiliense, 1999.

HOMERO. Odisseia. Tradução de Antônio Pinto de Carvalho. São Paulo: Abril, 1978.

HOMERO. Ilíada. Tradução de Manuel Odorico Mendes. São Paulo: Abril, 2009.

MARTINS, Maria Helena. O que é leitura. 19ª ed. São Paulo: Brasiliense, 1994.

MORIN, Edgar. Educação e complexidade. $4^{a}$ ed. São Paulo: Cortez, 2007.

ORLANDI, Eni Pulcinelli. Leitura perspectivas interdisciplinares. $5^{\text {a }}$ ed. São Paulo: Ática, 2005.

PLATÃO. República. Tradução Maria Helena da Rocha Pereira. 9. ed. Lisboa: Fundação

Calouste Gulbbenkian, 2001.

SERTILLANGES, A.D. A vida intelectual - seu espírito, suas condições, seus métodos. São Paulo: É Realizações, 2015.

SILVA, Ezequiel Teodoro da. O ato de ler: fundamentos psicológicos para uma nova pedagogia da leitura. 4. ed. São Paulo: Cortez Autores Associados, 1987.

VIRGÍLIO. Eneida. Tradução de Carlos Alberto Nunes; organização, apresentação e notas de João Angelo Oliva Neto. São Paulo: Editora 34, 2014. 